\title{
Dissociation of multiple memory systems by posttraining intracerebral injections of glutamate
}

\author{
MARK G. PACKARD \\ University of New Orleans, New Orleans, Louisiana \\ and Neuroscience Center of Excellence, Louisiana State University Medical Center, \\ New Orleans, Louisiana \\ and \\ LISA A. TEATHER \\ Neuroscience Center of Excellence, Louisiana State University Medical Center, \\ New Orleans, Louisiana
}

\begin{abstract}
The role of glutamatergic transmission in the memory functions of the hippocampus and the caudateputamen was examined using posttraining intracerebral injections of glutamate. Rats received an eighttrial (30-sec intertrial interval) training session on a hidden or visible platform task in a water maze. In the hidden platform task, a submerged escape platform was located in the same quadrant of the maze on all trials. In the visible platform task, a visible escape platform was located in a different quadrant of the maze on each trial. Following Trial 8 in either task, rats received a posttraining intrahippocampal or intracaudate injection of glutamate or saline. On a two-trial retention test session $24 \mathrm{~h}$ later, latency to mount the escape platform was used as a measure of memory. In the hidden platform task, the retention test escape latencies of rats receiving intrahippocampal injection of glutamate $(2 \mu \mathrm{g})$ were significantly lower than those of vehicle-treated rats, indicating an enhancement of memory. Intracaudate injection $(2,5$, or $10 \mu \mathrm{g})$ of glutamate had no effect on memory in the hidden platform task. In contrast, intracaudate injection of glutamate $(5 \mu \mathrm{g})$ enhanced memory in the visible platform task, whereas intrahippocampal injection $(1,2$, or $5 \mu \mathrm{g})$ had no effect. In both tasks and brain structures, intracerebral injections of glutamate had no effect on memory when delayed $2 \mathrm{~h}$ posttraining, indicating a timedependent effect of glutamate on memory storage processes. The findings indicate a double dissociation of the roles of the hippocampus and the caudate-putamen in memory and suggest that glutamate modulates the distinct forms of memory mediated by these two brain structures.
\end{abstract}

Evidence from both lesion and intracerebral posttraining drug administration studies provide support for the hypothesis that the mammalian hippocampus and caudate-putamen are parts of independent memory systems that differ in terms of the "type" of memory they mediate. In rats, lesions of the hippocampal system and caudate-putamen produce a double dissociation in acquisition of pairs of learning tasks with similar motivational, motor, and sensory characteristics. For example, lesions of the hippocampal system (Becker, Walker, \& Olton, 1980; McDonald \& White, 1993; Morris, Garrud, Rawlins, \& O'Keefe, 1982; Packard, Hirsh, \& White, 1989; Packard \& McGaugh, 1992), but not the caudate-putamen (Becker et al., 1980; Cook \& Kesner, 1988; McDonald \& White, 1993, 1994; Packard et al., 1989; Packard \& White, 1990; Packard, Winocur, \& White, 1992; but see also Whishaw, Mittleman, Bunch, \& Dunnett, 1987), im-

This research was supported by National Institutes of Health Grant R29MH56973-01 to M.G.P. The authors thank Mamta Mihimtura and Marisa Rubinow for surgical assistance. Correspondence should be addressed to M. G. Packard, who is now at the Department of Psychology, Yale University, 2 Hillhouse Ave., New Haven, CT 06520-8205 (e-mail: mark.packard@yale.edu). pair acquisition of win-shift radial maze and hidden platform water maze tasks. Conversely, lesions of the caudateputamen (McDonald \& White, 1993, 1994; Packard et al., 1989; Packard \& McGaugh, 1992), but not the hippocampal system (McDonald \& White, 1993, 1994; Morris et al., 1982; Packard et al., 1989; Packard \& McGaugh, 1992), impair acquisition of win-stay radial maze and visible platform water maze tasks. Other findings also indicate a double dissociation between the role of the hippocampus and caudate-putamen in tasks suggested to involve "allocentric" and "egocentric" spatial behavior, respectively (Abraham, Potegal, \& Miller, 1983; Cook \& Kesner, 1988; Kesner, Bolland, \& Dakis, 1993). For example, lidocaine injections into the hippocampus selectively impair the expression of place learning in a cross-maze, and similar injections into the caudate-putamen selectively impair expression of response learning (Packard \& McGaugh, 1996).

The memory-enhancing effects of posttraining intrahippocampal and intracaudate injections of the catecholamine agonist amphetamine are task-dependent: intrahippocampal injections selectively enhance memory in a win-shift radial maze task (Packard and White, 1991) and a hidden platform water maze task (Packard, 
Cahill, \& McGaugh, 1994; Packard \& Teather, 1998), and intracaudate injections selectively enhance memory in a win-stay radial maze task (Packard \& White, 1991) and a visible platform water maze task (Packard et al., 1994; Packard \& Teather, 1998).

An important question raised by the hypothesis that the hippocampus and caudate-putamen mediate different forms of memory involves the nature of the neurochemical bases of memory within these two brain structures. The present experiment focused on the role of the neurotransmitter glutamate in hippocampal-dependent and caudate-dependent memory. The rationale for examining glutamatergic influences on memory in these two brain structures is derived in part from evidence that glutamate is the principal neurotransmitter in cortical pathways providing sensory information to both systems. The rat caudate-putamen receives an extensive glutamatergic innervation via the corticostriatal pathway, and it contains $\mathrm{N}$-methyl-D-aspartate (NMDA), kainate, and metabotropic glutamate receptors (for review, see Ottersen, Hjelle, Osen, $\&$ Laake, 1995). The hippocampus receives a primary glutamatergic projection from the entorhinal cortex via the perforant path, and contains a high density of NMDA, kainate, and metabotropic glutamate receptors (for review, see Otterson and Storm-Mathisen, 1989). In addition, findings of numerous studies employing peripheral (e.g., Packard \& Teather, 1997b; Robinson, Crooks, Shinkman, \& Gallagher, 1989; Shapiro \& Caramanos, 1990; Ward, Mason, \& Abraham, 1990), intracerebroventricular (e.g., Flood, Baker, \& Davis, 1990; Holscher, McGlinchey, \& Rowan, 1996; Morris, Anderson, Lynch, \& Baudry, 1986; Riedel, Wetzel, \& Reymann, 1996), and intracerebral (e.g., Izquierdo et al., 1992; Kim \& McGaugh, 1992; Miserendino, Sananes, Melia, \& Davis, 1990; Morris, Halliwell, \& Bowery, 1989) injection of drugs affecting various glutamate receptor subtypes suggest a role for glutamate transmission in learning and memory.

We recently observed a task-dependent impairment of memory following posttraining intrahippocamal and intracaudate injections of the glutamate NMDA receptor antagonist 2-amino-phosphonopentanoic acid (AP5; Packard \& Teather, 1997a). Posttraining intrahippocampal, but not intracaudate, injections of AP5 impaired memory in rats trained in a hidden platform water maze task. In this task, rats learn to approach a consistently located hidden escape platform from different start points around the perimeter of the maze. In contrast, posttraining intracaudate, but not intrahippocampal, injections of AP5 impaired memory in rats trained in a visible platform water maze task. In this task, rats learn to approach a visible platform that is located in a different quadrant of the maze on each trial. These findings suggest a role for NMDA glutamate receptors in the distinct memory processes subserved by the hippocampus and caudate-putamen and raise the possibility that posttraining activation of glutamate receptors may enhance memory in a task-dependent manner following intrahippocampal and intracaudate in- jection. To examine this hypothesis in the present study, rats were trained in either the hidden or the visible platform water maze task and received a posttraining intracerebral injection of glutamate or saline into either the hippocampus or the caudate-putamen.

\section{METHOD}

\section{Subjects}

The subjects were 139 male Long-Evans rats $(275-300 \mathrm{~g})$, individually housed in a temperature-controlled 12:12-h light:dark cycle. Lights were on in the colony room from 7 a.m. to 7 p.m. The animals were given ad-lib access to food and water.

\section{Apparatus}

The water maze was a black circular tank $6 \mathrm{ft}$ in diameter and $1.5 \mathrm{ft}$ in height. The tank was filled with water $\left(25^{\circ} \mathrm{C}\right)$ to a depth of $20 \mathrm{~cm}$ and was located in a room containing several extramaze cues. Four starting positions (north $[N]$, south [S], east $[\mathrm{E}]$, and west $[\mathrm{W}]$ ) were equally spaced around the perimeter of the tank, dividing the pool into four equal quadrants. The rectangular Plexiglas escape platform used for the spatial task $(11 \times 14 \times 19 \mathrm{~cm})$ was submerged at a depth of $1 \mathrm{~cm}$. For the visible platform water maze task, a white rubber ball ( $8 \mathrm{~cm}$ in diameter) was attached to the top of the submerged platform and protruded above the water surface.

\section{Surgery}

The rats were anesthetized with $50 \mathrm{mg} / \mathrm{kg}$ sodium pentobarbital, and unilateral guide cannulae $(15 \mathrm{~mm}$ in length for the caudateputamen placements and $10 \mathrm{~mm}$ in length for hippocampal placements) were implanted using standard stereotaxic techniques. The cannulae were anchored to the skull with jewelers screws and dental acrylic. For the caudate-putamen placements, coordinates for the guide cannulae were $\mathrm{AP}=-0.3 \mathrm{~mm}, \mathrm{ML}=4.0 \mathrm{~mm}$ from bregma and $\mathrm{DV}=-5.0 \mathrm{~mm}$ from the skull surface. Coordinates for the dorsal hippocampal placements were $\mathrm{AP}=-3.1 \mathrm{~mm}, \mathrm{ML}=$ $1.5 \mathrm{~mm}$ from bregma, and DV $=-2.0 \mathrm{~mm}$ from the skull surface. These coordinates were based on our previous findings indicating that posttraining injection of the glutamate NMDA receptor antagonist AP5 into these hippocampal and caudate-putamen sites impairs memory (Packard and Teather, 1997a). After surgery, stylets were inserted and left in place to ensure cannula patency until injections were made. Behavioral testing began 1 week after surgery.

\section{Drugs/Injection Procedures}

Glutamate (glutamic acid; Research Biochemicals International) was dissolved in physiological saline. The doses used in the doseresponse curve generated for intrahippocampal injections $(1,2$, and $5 \mu \mathrm{g}$ ) were selected on the basis of findings indicating that posttraining intrahippocampal injection of $5 \mu \mathrm{g}$ of glutamate enhances memory in an inhibitory avoidance task (Izquierdo et al., 1992). The doses used in the dose-response curve generated for intracaudate injections $(2,5$, and $10 \mu \mathrm{g})$ were selected on the basis of evidence of a more moderate glutamate receptor density in the rat caudate-putamen relative to the hippocampus (Ottersen et al., 1995). Injections $(0.5 \mu \mathrm{l})$ were administered intracerebrally via guide cannulae using 30 -ga injection needles connected by polyethylene tubing to $10-\mu 1$ Hamilton microsyringes. The injections were delivered over $37 \mathrm{sec}$ using an electronically timed microsyringe pump, and the injection needles (extending $1 \mathrm{~mm}$ from the end of the guide cannulae) were left in place an additional $60 \mathrm{sec}$ to allow for diffusion of solution away from the needle tip.

\section{Histology}

After behavioral testing, the animals were anesthetized with a $1-$ $\mathrm{cc}$ injection of sodium pentobarbital $(50 \mathrm{mg} / \mathrm{cc})$ and perfused with 
saline followed by a $10 \%$ formal-saline solution. Brains were removed and fixed in a $10 \%$ formal-saline solution before slicing. The brains were sectioned at $20-\mu \mathrm{m}$ sections through the cannulae tract region, stained with cresyl violet, and mounted. The slides were examined for verification of cannulae placement and injection needle tip location using the atlas of Paxinos and Watson (1986).

Results of the histological examination are shown in Figures 1 and 2. The hippocampal placements (Figure 1) were located in the dorsal hippocampus, ranging from $-2.80 \mathrm{~mm}$ to $-3.30 \mathrm{~mm}$ anterior-posterior from bregma. For the posteroventral caudate-putamen placements (Figure 2), the injection needle tips ranged from $-0.20 \mathrm{~mm}$ to $-0.40 \mathrm{~mm}$ anterior-posterior from bregma.

\section{Behavioral Procedures}

Hidden platform water maze task. The behavioral procedures for both of the water maze tasks were similar to those previously described (e.g., Packard et al., 1994; Packard \& McGaugh, 1994). The rats received one training session consisting of eight trials (i.e., swims). On each trial, the rat was placed into the tank facing the wall at one of the four designated starting points $(\mathrm{N}, \mathrm{S}, \mathrm{E}$, or $\mathrm{W})$ and was allowed to escape onto the hidden platform. The submerged escape platform was located in the same quadrant on every trial. A different starting point was used on each trial such that each starting point was used twice within the eight trials. If the rat did not escape within $60 \mathrm{sec}$, it was manually guided to the escape platform. After mounting the platform, the rat remained on the platform for $20 \mathrm{sec}$. Following each trial, it was removed from the maze and placed in a holding cage for a 30 -sec intertrial interval (ITI). The latency to mount the escape platform was recorded and used as a measure of task acquisition.

The rats randomly assigned to treatment groups were given an injection of glutamate or saline into either the hippocampus ( $1 \mu \mathrm{g}, n=$ 9; $2 \mu \mathrm{g}, n=8$; or $5 \mu \mathrm{g}, n=9$; saline, $n=9$ ) or the caudate-putamen $(2 \mu \mathrm{g}, n=7 ; 5 \mu \mathrm{g}, n=9$; or $10 \mu \mathrm{g}, n=8$; saline, $n=9$ ) immediately after training (i.e., Trial 8). A two-trial retention test was conducted $24 \mathrm{~h}$ after the completion of training. The submerged escape platform was located in the same quadrant of the maze as during training, and the starting points used on the retention test trials were

\section{Dorsal Hippocampus}

Hidden platform task

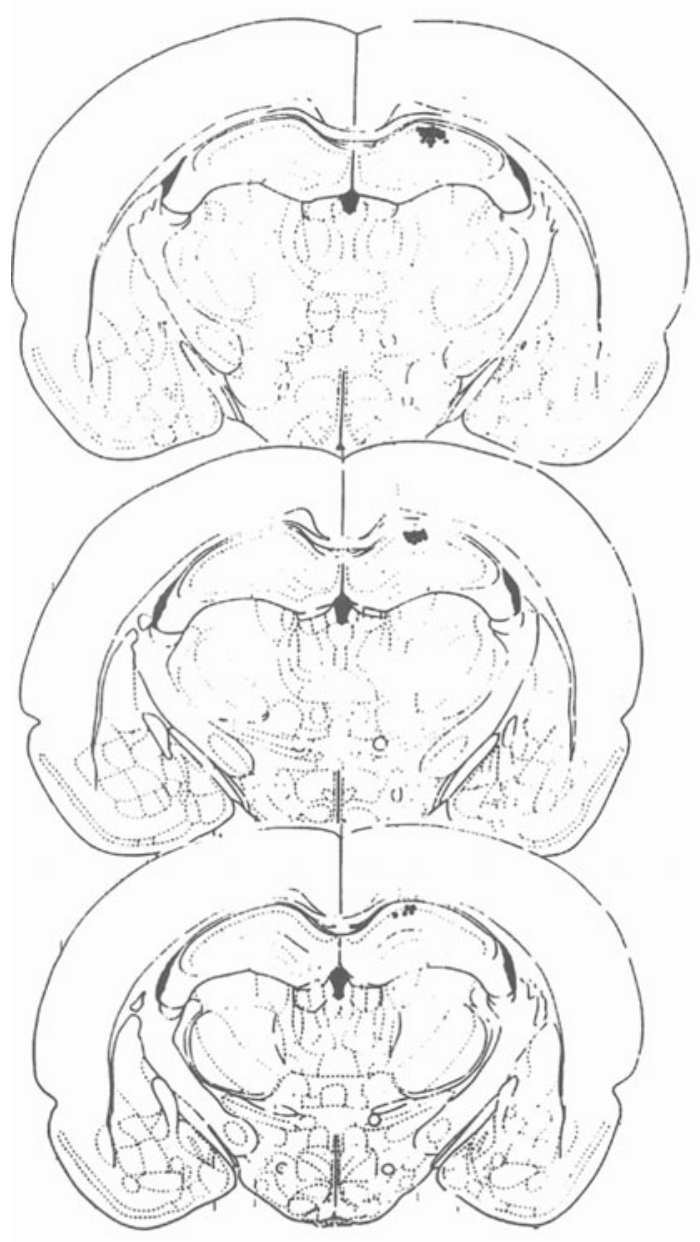

Visible platform task

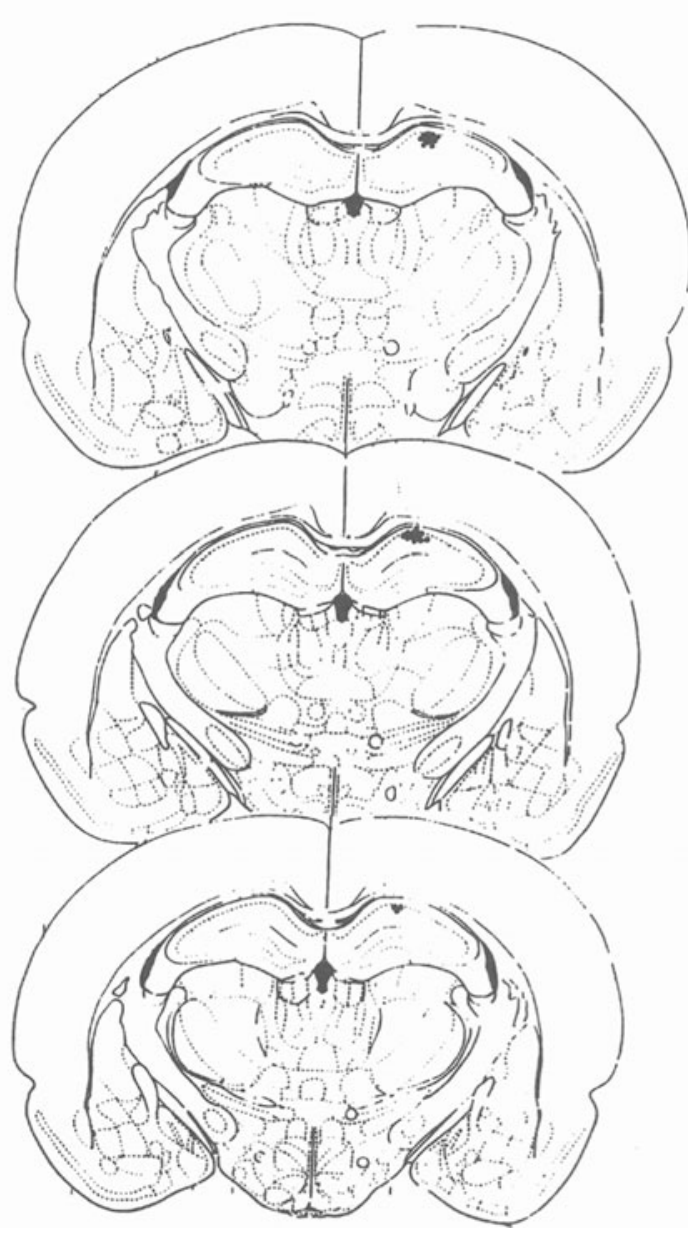

Figure 1. Dorsal hippocampus needle tip placements for the hidden platform task (left) and the visible platform task (right). Top: $-2.80 \mathrm{~mm}$ AP from bregma. Middle: $-3.14 \mathrm{~mm}$ AP from bregma. Bottom: $-3.30 \mathrm{~mm}$ AP from bregma. Verification from atlas of Paxinos and Watson (1986). 


\section{Posteroventral Caudate}

Hidden platform task

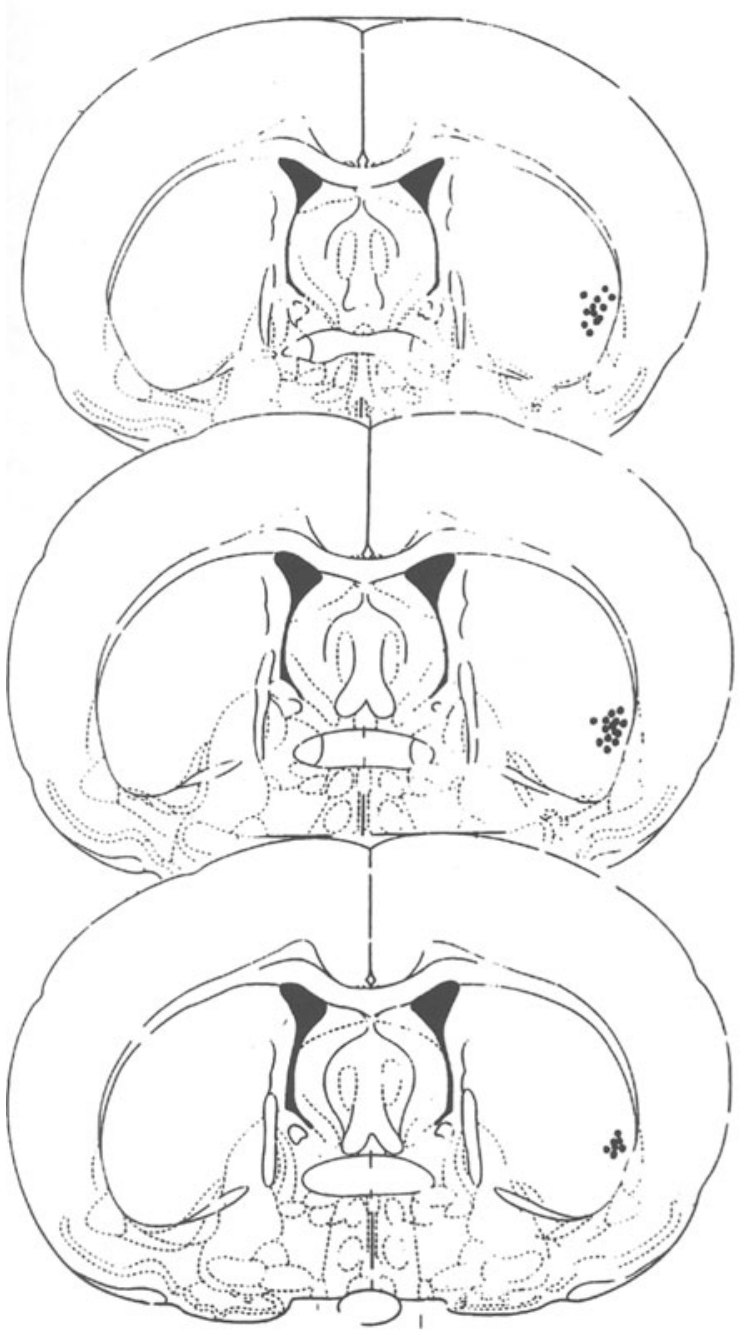

Visible platform task

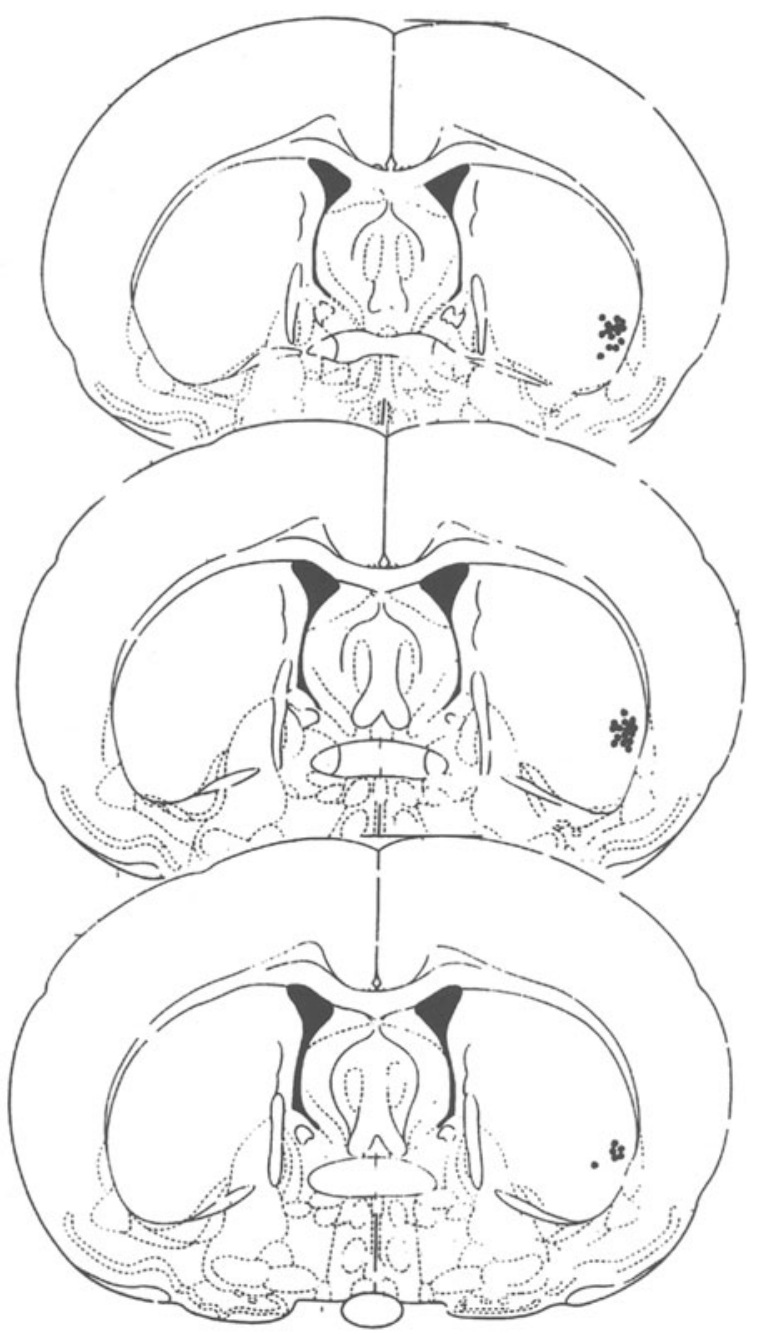

Figure 2. Posteroventral caudate-putamen needle tip placements for the hidden platform task (left) and the visible platform task (right). Top: $-0.26 \mathrm{~mm}$ AP from bregma. Middle: $-0.30 \mathrm{~mm}$ AP from bregma. Bottom: $-0.40 \mathrm{~mm}$ AP from bregma. Verification from atlas of Paxinos and Watson (1986).

located distal to the escape platform. Latency to mount the escape platform was recorded on the retention test trials and used as a measure of memory for the previous day's training session.

An additional group of rats received identical training and retention testing but were given intrahippocampal injections of glutamate $(2 \mu \mathrm{g}, n=6) 2 \mathrm{~h}$ posttraining. The delayed posttraining injection group was run in order to control for possible nonmnemonic effects of the immediate injections on retention, and the dose of glutamate used for the delayed injections was chosen after examining the effectiveness of the immediate posttraining injections.

Visible platform water maze task. The rats received one training session consisting of eight trials (i.e., swims). On each trial, the rat was placed into the tank facing the wall at one of the four designated starting points $(\mathrm{N}, \mathrm{S}, \mathrm{E}$, or W) and was allowed to escape onto the visibly cued platform. A different starting point was used on each trial such that each starting point was used twice within the eight trials. The visible escape platform was placed in a different quadrant on each trial such that each of the four quadrants contained the escape platform on two of the eight trials. The locations of the starting points were arranged so that distance to the platform (i.e., proximal or distal) and location of the platform relative to the start point (i.e., left or right) were counterbalanced across the eight trials. If the rat did not escape within $60 \mathrm{sec}$, it was manually guided to the escape platform. After mounting the platform, the rat remained on the platform for $20 \mathrm{sec}$. Following each trial, it was removed from the maze and placed in a holding cage for a $30-\mathrm{sec}$ ITI. The latency to mount the escape platform was recorded and used as a measure of task acquisition. 
The rats randomly assigned to treatment groups were given an injection of glutamate or saline into either the hippocampus $(1 \mu \mathrm{g}, n=$ $7 ; 2 \mu \mathrm{g}, n=7$; or $5 \mu \mathrm{g}, n=6$; saline, $n=8$ ) or caudate-putamen $(2 \mu \mathrm{g}, n=7 ; 5 \mu \mathrm{g}, n=8$; or $10 \mu \mathrm{g}, n=8$; saline, $n=9)$ immediately after training (i.e., Trial 8). A two-trial retention test was conducted $24 \mathrm{~h}$ after completion of the training, and the starting points used on the retention test trials were located distal to the escape platform. Latency to mount the escape platform was recorded on the retention test trials and was used as a measure of memory for the previous day's training session.

An additional group of rats received identical training and retention testing but were given intracaudate injections of glutamate $(5 \mu \mathrm{g}$, $n=5) 2 \mathrm{~h}$ posttraining. The dose of glutamate used for the delayed injections was chosen after examining the effectiveness of the immediate posttraining injections.

\section{RESULTS}

\section{Hidden Platform Water Maze Task}

Hippocampus. A two-way one repeated measures analysis of variance (ANOVA) computed on the escape latencies on the training day (i.e., prior to the posttraining injections) revealed no significant group effect $[F(4,36)=$ 1.80 , n.s.] or group $\times$ trial interaction $[F(4,28)=1.41$, n.s.]. A significant trial effect $[F(4,7)=61.1, p<.01]$ indicated that the rate of task acquisition was similar in all groups. The mean escape latencies in seconds on Trials 7 and 8 (i.e., the final two trials) and the standard errors of the mean $(S E M \mathrm{~s})$ on Trial 8 were as follows: saline, 9.7, $S E M=1.83$; glutamate $1.0 \mu \mathrm{g}, 10.3, S E M=1.51$; glutamate $2.0 \mu \mathrm{g}, 9.25, S E M=2.56$; glutamate $5.0 \mu \mathrm{g}, 9.13$, $S E M=2.80$; glutamate $2.0 \mu$ g delayed, $8.35, S E M=2.82$. The lack of group differences in escape latencies during training indicates that any differences in retention test performance among the treatment groups were not due to differential rates of task acquisition.

The effect of posttraining intrahippocampal injections of glutamate on memory in the hidden platform water maze task is illustrated in Figure 3 (top). A two-way one repeated measures ANOVA computed on the retention test escape latencies revealed a significant group $\times$ trial interaction $[F(1,3)=3.37, p<.05]$ and a significant trial effect $[F(1,3)=5.96, p<.05]$. Tests of simple main effects (group within trial) indicated significant group differences on Retention Test Trial $1[F(3,31)=3.41, p<$ $.05]$. Fisher's LSD post hoc tests showed that posttraining injection of glutamate at a dose of $2 \mu \mathrm{g}$ significantly enhanced memory $(p<.05)$, whereas doses of $1 \mu \mathrm{g}$ and $5 \mu \mathrm{g}$ had no effect on retention. There were no significant group differences on Retention Test Trial $2[F(3,31)=0.670$, n.s.], since the performance of the saline-treated rats improved to the level of the rats treated with the $2-\mu \mathrm{g}$ dose of glutamate.

Intrahippocampal injections of glutamate $(2 \mu \mathrm{g})$ administered $2 \mathrm{~h}$ posttraining did not affect retention test performance relative to the performance of the salinetreated rats [group $\times$ trial interaction, $F(1,1)=0.776$, n.s.; group effect, $F(1,13)=0.502$, n.s.], indicating that the effect of the immediate posttraining injections of glutamate was not due to a proactive drug effect on task performance.

Caudate-putamen. A two-way one repeated measures ANOVA revealed no significant group effect $[F(3,29=$ 0.73$, n.s. $]$ or group $\times$ trial interaction $[F(3,21)=1.15$, n.s.] in training-day escape latencies. A significant trial effect $[F(3,7)=74.1, p<.01]$ indicated that the rate of task acquisition was similar in all groups. The mean escape latencies in seconds on Training Trials 7 and 8 and the SEMs on Trial 8 were as follows: saline, 7.53, SEM = 2.76; glutamate $2.0 \mu \mathrm{g}, 7.19, S E M=1.14$; glutamate $5.0 \mu \mathrm{g}, 6.79, S E M=1.07$; glutamate $10.0 \mu \mathrm{g}, 9.65$, $S E M=1.53$.

The effect of posttraining intracaudate injections of glutamate on memory in the hidden platform water maze task is shown in Figure 3 (bottom). A two-way one repeated measures ANOVA computed on the retention test latencies revealed no significant group effect $[F(3,29)=0.744$, n.s.] or group $\times$ trial interaction $[F(1,3)=0.048$, n.s. $]$, indicating that intracaudate injections of glutamate $(2,5$, or $10 \mu \mathrm{g}$ ) had no effect on retention in the hidden platform task. A significant effect of trial $[F(1,3)=30.62, p<$ $.01]$ indicated that all groups improved in escape latency over the two retention test trials.

\section{Visible Platform Water Maze Task}

Caudate-putamen. A two-way one repeated measures ANOVA computed on the escape latencies on the training day revealed no significant group effect $[F(4,32)=$ 0.194 , n.s. $]$ or group $\times$ trial interaction $[F(4,28)=0.77$, n.s.]. A significant trial effect $[F(4,7)=59.44, p<.01]$ indicated that the rate of task acquisition was similar in all groups. The mean escape latencies in seconds on Trials 7 and 8 and the SEMs on Trial 8 were as follows: saline, $8.27, S E M=2.01$; glutamate $2.0 \mu \mathrm{g}, 9.90, S E M=$ 1.27; glutamate $5.0 \mu \mathrm{g}, 8.96, S E M=2.21$; glutamate $10.0 \mu \mathrm{g}, 9.80, S E M=1.34$; glutamate $5.0 \mu \mathrm{g}$ delayed, $11.80, S E M=3.27$. The lack of group differences in escape latencies during training indicates that any differences in retention test performance among the treatment groups were not due to differential rates of task acquisition.

The effect of posttraining intracaudate injections of glutamate on memory in the visible platform water maze task is illustrated in Figure 4 (top). A two-way one repeated measures ANOVA computed on the retention test latencies revealed a significant group $\times$ trial interaction $[F(1,3)=$ $5.32, p<.01]$, a significant group effect $[F(3,28)=7.26$, $p<.01]$, and a significant trial effect $[F(1,3)=20.76$, $p<.01]$. Tests of simple main effects (group within trial) indicated a significant group difference on Retention Test Trial $1[F(3,28)=7.55, p<.01]$. Fisher's LSD post hoc tests showed that posttraining injection of glutamate at a dose of $5 \mu \mathrm{g}$ significantly enhanced memory $(p<.05)$, whereas doses of $2 \mu \mathrm{g}$ and $10 \mu \mathrm{g}$ had no effect on retention. There were no significant group differences on $\mathrm{Re}$ - 
tention Test Trial $2[F(3,28)=0.865$, n.s. $]$, since the performance of the saline-treated rats improved to the level of the rats treated with the 5- $\mu \mathrm{g}$ dose of glutamate.

Intracaudate injections of glutamate $(5 \mu \mathrm{g})$ administered $2 \mathrm{~h}$ posttraining did not affect retention test performance relative to the performance of the saline-treated rats [group $\times$ trial interaction, $F(1,1)=0.005$, n.s.; group effect, $F(1,12)=0.796$, n.s.], indicating that the effect of the immediate posttraining injections of glutamate was not due to a proactive drug effect on task performance.

Hippocampus. There was no significant group difference $[F(3,25)=0.63$, n.s.] or group $\times$ trial interaction
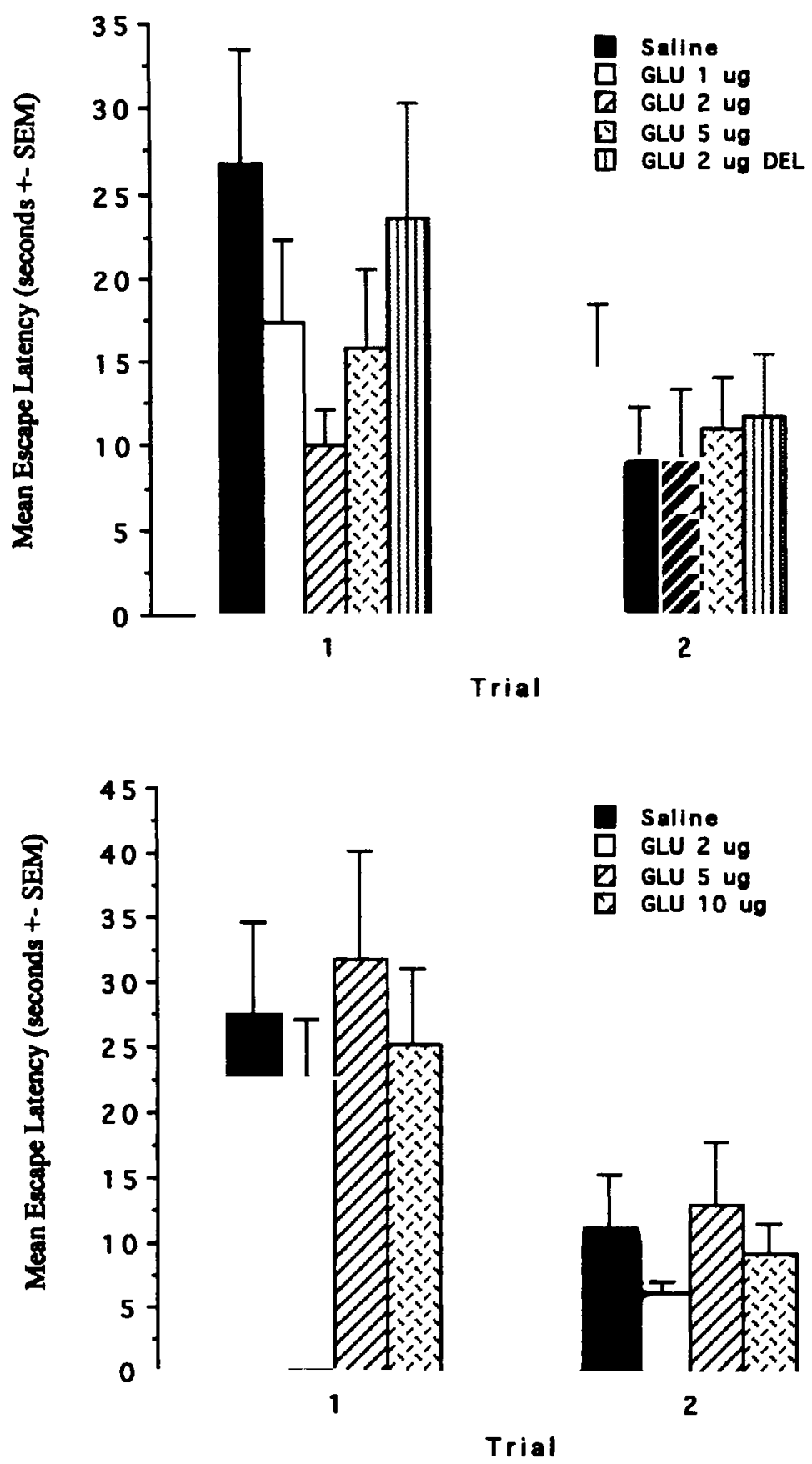

Figure 3. Mean retention test escape latencies of rats receiving posttraining intrahippocampal (top) and intracaudate (bottom) injections of glutamate on memory in a hidden platform water maze task. Intrahippocampal injections of glutamate ( $2 \mu \mathrm{g})$ enhanced memory relative to saline controls, whereas intracaudate injections had no effect. DEL = delayed injection ( $2 \mathrm{~h}$ posttraining). 
$[F(3,21)=1.40$, n.s. $]$ in training-day escape latencies. A significant trial effect $[F(3,7)=42.26, p<.01]$ indicated that the rate of task acquisition was similar in all groups. The mean escape latencies in seconds on Trials 7 and 8 and the $S E M$ s on Trial 8 were as follows: saline, 9.37, $S E M=3.86$; glutamate $1.0 \mu \mathrm{g}, 10.70, S E M=2.15$; glu- tamate $2.0 \mu \mathrm{g}, 8.37, S E M=1.84$; glutamate $5.0 \mu \mathrm{g}, 6.83$, $S E M=1.76$.

The effect of posttraining intrahippocampal injections of glutamate on memory in the visible platform water maze task is shown in Figure 4 (bottom). A two-way one repeated measures ANOVA computed on the retention
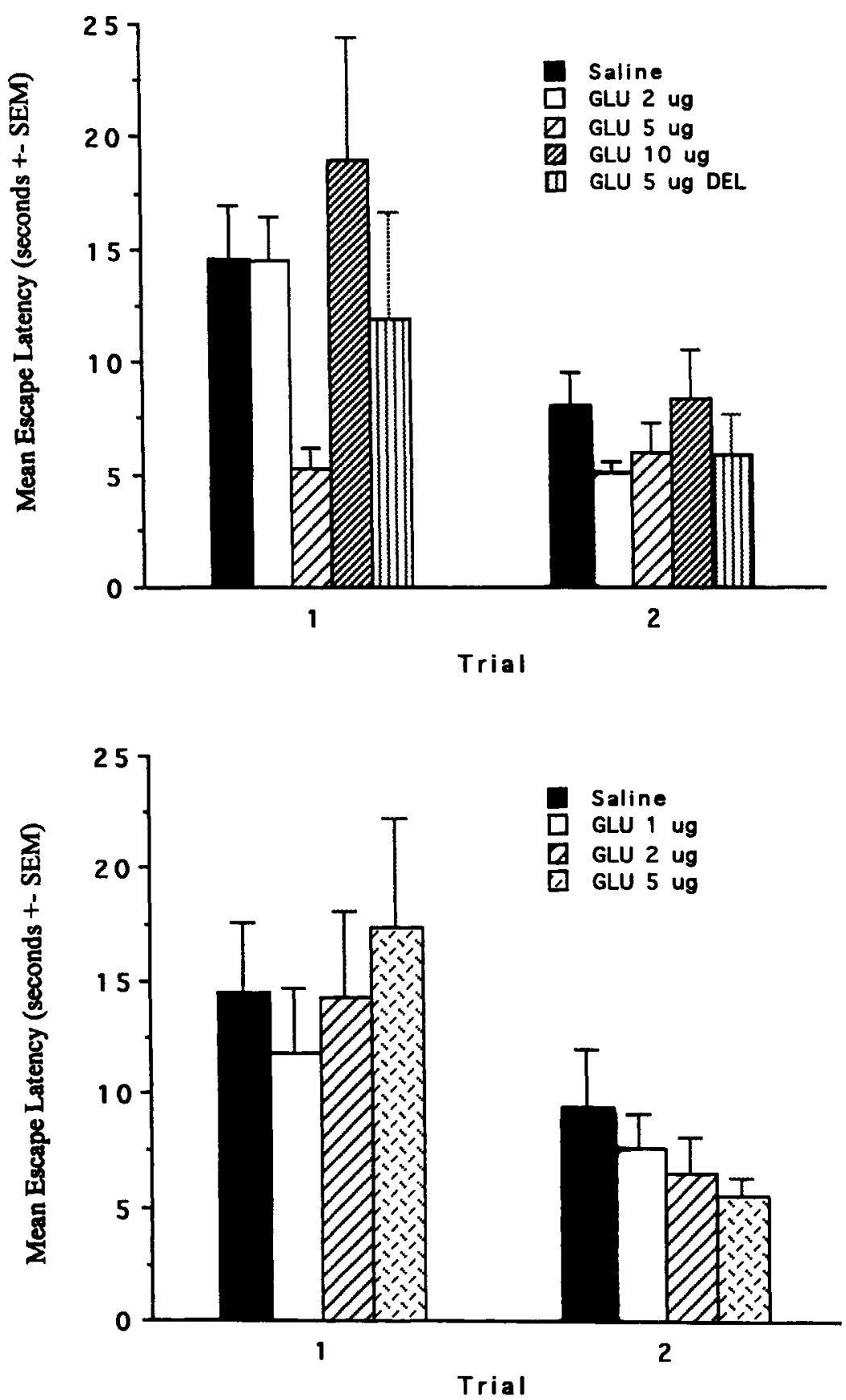

Figure 4. Mean retention test escape latencies of rats receiving posttraining intracaudate (top) and intrahippocampal (bottom) injections of glutamate on memory in a visible platform water maze task. Intracaudate injections of glutamate $(5 \mu \mathrm{g})$ enhanced memory relative to saline controls, whereas intrahippocampal injections had no effect. DEL = delayed injection ( 2 h posttraining). 
test escape latencies revealed no significant group effect $[F(3,25)=0.563$, n.s. $]$ or group $\times$ trial interaction $[F(1,3)$ $=1.23$, n.s.], indicating that intrahippocampal injections of glutamate $(1,2$, or $5 \mu \mathrm{g})$ had no effect on retention in the visible platform task. A significant effect of trial $[F(1,3)=33.70, p<.01]$ indicated that all groups improved in escape latency over the two retention test trials.

\section{DISCUSSION}

\section{Double Dissociation of Hippocampal and Caudate-Putamen Memory Systems}

Posttraining intrahippocampal injection of glutamate enhanced memory in the hidden platform water maze task, whereas intracaudate injections of glutamate had no effect. In contrast, posttraining intracaudate injection of glutamate enhanced memory in the visible platform water maze task, whereas intrahippocampal injections of glutamate had no effect. The findings are consistent with previous demonstrations of double dissociations in task acquisition following lesions of the hippocampal system and the caudate-putamen (Kesner et al., 1993; McDonald \& White, 1993, 1994; Packard et al., 1989; Packard \& McGaugh, 1992, 1996) and posttraining intracerebral injections of amphetamine (Packard et al., 1994; Packard \& Teather, 1998; Packard \& White, 1991).

The important factor underlying the effects of hippocampal and caudate-putamen manipulations appears to be the type of memory required for task acquisition, since each of these lesion and drug-injection studies used pairs of tasks with similar motivational, motoric, and sensory characteristics. Moreover, in both water maze tasks and brain structures, injections of glutamate delayed $2 \mathrm{~h}$ posttraining had no effect on retention. The timedependent nature of glutamate-induced memory enhancement indicates that the effects were not due to a proactive action on nonmnemonic factors (e.g., swim speed, motivation, or sensory processes) and suggests that glutamate administration enhanced memory storage processes (McGaugh, 1966, 1973, 1989). The task-dependent effects of intrahippocampal and intracaudate injections of glutamate on memory in the hidden and visible platform water maze tasks also suggest an enhancement of memory processes specific to each task, and not memory enhancement for a learned "strategy" common to each task.

The psychological operating principles that distinguish hippocampal and caudate-putamen memory processes may be understood by considering various "dual-memory" theories that have been proposed on the basis of the pattern of impaired and spared learning ability observed following damage to the hippocampal system. Thus, acquisition of the hidden platform water maze task may involve learning the spatial location of the platform relative to the topographical relationships among extramaze cues, a hippocampal-dependent learning process that may involve cognitive (Hirsh, 1974; Mishkin \& Petri, 1984), spatial (O'Keefe \& Nadel, 1978), configural (Sutherland \& Rudy, 1989), or declarative (Cohen \& Eichen- baum, 1993; Cohen \& Squire, 1980) memory. In contrast, acquisition of the visible platform water maze task may involve learning an approach response to a specific visual stimulus, a caudate-dependent learning process that may involve habit (Hirsh, 1974; Mishkin \& Petri, 1984), taxon (O’Keefe \& Nadel, 1978), simple associative (Sutherland \& Rudy, 1989), or procedural (Cohen \& Eichenbaum, 1993; Cohen \& Squire, 1980) memory.

\section{Glutamate Modulation of Hippocampal and Caudate-Putamen Memory Processes}

Consistent with previous findings using an inhibitory avoidance task (Izquierdo et al., 1992), posttraining intrahippocampal injections of glutamate enhanced memory in the hidden platform water maze task. Other findings indicate that posttraining intrahippocampal injection of the NMDA glutamate receptor antagonist AP5 impairs memory in the hidden platform water maze task (Liang, 1994; Packard \& Teather, 1997a). To our knowledge, the present findings are the first to demonstrate a memoryenhancing effect of posttraining intracaudate injections of glutamate. Other findings indicate that posttraining intraamygdala injections of glutamate (Izquierdo et al., 1992) and glutamate NMDA receptor antagonists (Izquierdo et al., 1992; Jerusalinsky et al., 1992; Kim \& McGaugh, 1992; Liang, Hon, \& Davis, 1994) also influence memory storage processes. Thus, there appears to be a widespread role for brain glutamatergic systems in memory modulation.

In previous work, we have observed that infusion of cresyl violet dye into the dorsal hippocampus and posteroventral caudate using the present injection parameters results in tissue stain largely confined to the intended target. Converging evidence from lesion studies indicating a selective role for the hippocampal system and the caudate-putamen in acquisition of spatial and cued water maze tasks (e.g., McDonald \& White, 1994; Packard \& McGaugh, 1992) also supports the hypothesis that the glutamate injections likely acted within these brain sites to enhance memory. However, in the absence of autoradiographic analyses, the possibility that the glutamate injections may have enhanced memory via spread to other brain regions cannot be completely ruled out at present.

Two features of the dose-dependent nature of the memory-enhancing effects of intracerebral glutamate were observed in the present study. First, the effective memory enhancing doses in the hippocampus $(2 \mu \mathrm{g})$ and the caudate-putamen $(5 \mu \mathrm{g})$ were different. This difference may reflect the lower densities of glutamate receptors in the caudate-putamen relative to the hippocampus (e.g., Ottersen et al., 1995) and/or a difference in the level of glutamate receptor activation necessary to enhance the distinct type of memory subserved by each structure. Alternatively, given the existence of multiple receptor subtypes for glutamate (Ottersen et al., 1995; Otterson \& Storm-Mathisen, 1989), the difference in effective doses in the hippocampus and the caudate-putamen may reflect a differential mnemonic role of various gluta- 
mate receptors subtypes in each structure. A second feature of the effects of posttraining glutamate is the existence of an "inverted-U" dose-response curve for injections in both the hippocampus and the caudate-putamen; an intermediate dose in the curve was effective, whereas lower and higher doses did not affect retention. These findings suggest that an optimal level of glutamate receptor activation is necessary in order to produce memory-enhancing effects. The presence of inverted- $U$ doseresponse curves over a range of treatments affecting numerous neurotransmitter and hormonal systems suggests that they represent a fundamental aspect of posttraining drug effects on memory (for review, see Martinez, 1986).

\section{Possible Mechanisms of Glutamate-Induced Memory Enhancement}

The rat hippocampus and caudate-putamen contain multiple glutamate receptor subtypes, including NMDA, AMPA, and metabotropic glutamate receptors (Ottersen et al., 1995; Otterson \& Storm-Mathisen, 1989). The use of the endogenous ligand in the present study precludes any knowledge of the role of specific glutamate receptor subtypes in the observed memory-enhancing effects. However, our previous findings indicate that posttraining intrahippocampal and intracaudate injections of the glutamate NMDA receptor antagonist AP5 impair memory in a task-dependent manner in the two water maze tasks (Packard \& Teather, 1997a), suggesting that activation of NMDA receptors in part mediates the memory-enhancing effects of glutamate. NMDA receptor activation and subsequent calcium influx mediate the induction of hippocampal long-term potentiation (LTP), a putative physiological mechanism of memory formation (for reviews, see Bliss \& Collinridge, 1993, and Maren, 1995; but see also Holscher, Anwyl, \& Rowan, 1997, and McEachern \& Shaw, 1996). Calcium influx following NMDA receptor activation results in the production and/or release of putative retrograde messengers involved in the maintenance of hippocampal LTP (for review, see Medina \& Izquierdo, 1995) and could possibly mediate the memory-enhancing effects of posttraining intrahippocampal glutamate injection.

With regards to the caudate-putamen, recent evidence indicates that tetanic stimulation influencing corticostriatal fibers induces long-term changes in neuronal plasticity in the rat caudate-putamen (e.g., Calabresi, Maj, Pisani, Mercuri, \& Bernardi, 1992; Calabresi, Pisani, Mercuri, \& Bernardi, 1993; Charpier \& Deniau, 1997; GarciaMunoz \& Groves, 1992). On the basis of findings from in vitro preparations, it has been hypothesized that longterm depression (LTD) of striatal EPSPs represents a possible mechanism of synaptic modification underlying the role of the caudate in "motor" memory (Calabresi et al., 1992; Calabresi et al., 1993). However, this hypothesis has been challenged by recent findings from in vivo preparations, in which it has been suggested that LTP of striatal EPSPs represents the primary form of synaptic plasticity induced by corticostriatal stimulation (Charpier \& Deniau, 1997). The extent to which an "LTDor LTP-like" mechanism may mediate the mnemonic functions of the caudate-putamen has not been directly investigated. However, since glutamate is the principal neurotransmitter in corticostriatal fibers (Fonnum, StormMathiesen, \& Divac, 1981), our behavioral data are consistent with the hypothesis that a long-term enhancement of corticostriatal plasticity may mediate the memoryenhancing effects of intracaudate administration of glutamate.

Finally, the memory-enhancing effects of glutamate may involve an interaction with other neurotransmitter systems. This suggestion is based on evidence indicating that glutamate modulates the release of several neurotransmitters, including acetylcholine (Giovannini et al., 1995), norepinephrine (Navarro, Cabrena, \& Donoso, 1995), and dopamine (Krebs et al., 1991; Whitton, Maione, Biggs, \& Fowler, 1994), and each of these transmitters is known to individually influence posttraining memory processes (McGaugh, 1966, 1973, 1989). Moreover, recent behavioral evidence suggests that glutamate interacts with cholinergic (Castellano, Mele, \& Oliverio, 1996; Matsuoka \& Aigner, 1996), noradrenergic (Ohno, Yoshimatsu, Kobayashi, \& Watanabe, 1996), and dopaminergic (Mele, Castellano, Cestari, \& Oliverio, 1995) systems in memory. A glutamate-dopamine interaction in the memory processes mediated by the hippocampus and the caudate-putamen is suggested by our previous findings indicating that posttraining injection of dopamine agonists into the same sites as those used in the present study enhances memory (Packard et al., 1994; Packard \& Teather, 1997a; Packard \& White, 1991). In the caudate-putamen, dopamine may modulate sensory input from corticostriatal glutamatergic projections to influence stimulus-response habit formation. The extent to which dopaminergic input to the hippocampus (for review, see Gasbarri, Sulli, \& Packard, 1997) interacts with glutamatergic cortical input to modulate hippocampal memory processes is unknown; however, dopamine antagonists have been reported to block the "maintenance" of hippocampal LTP (Frey, Hartmann, \& Matthies, 1989).

In summary, the present findings indicate a double dissociation between the roles of the hippocampus and the caudate-putamen in memory and are consistent with the hypothesis that these two brain structures are parts of independent memory systems. In addition, the findings suggest that glutamate modulates memory in both systems. Findings indicating that the distinct mnemonic functions of the hippocampus and the caudate-putamen are mediated by similar neurotransmitters (e.g., glutamate and dopamine) suggest an evolutionary conservation of the role of neurochemical systems in modulating the multiple forms of memory existing in the mammalian brain. 


\section{REFERENCES}

Abraham, L., Potegal, M., \& Miller, S. (1983). Evidence for caudate nucleus involvement in an egocentric spatial task: Return from passive transport. Physiological Psychology, 11, 11-17.

Becker, J. T., Walker, A., \& Olton, D. S. (1980). Neuroanatomical basis of spatial memory. Brain Research, 200, 307-320.

Bliss, T. V. P., \& Collinridge, G. L. (1993). A synaptic model of memory: Long-term potentiation in the hippocampus. Nature, 361, 31-39.

Calabresi, P., Maj, R., Pisani, A., Mercuri, N. B., \& Bernardi, G. (1992). Long-term synaptic depression in the striatum: Physiological and pharmacological characterization. Journal of Neuroscience, 12, $4224-4233$.

Calabresi, P., Pisani, A., Mercuri, N. B., \& Bernardi, G. (1993). Long-term potentiation in the striatum is unmasked by removing the voltage dependent blockade of NMDA receptor channel. European Journal of Neuroscience, 4, 929-935.

Castellano, C., Mele, A., \& Oliverio, A. (1996). Glutamatergiccholinergic interaction on memory consolidation in mice. Psychobiology, 24, 57-61.

Charpier, S., \& Deniau, J. M. (1997). In vivo activity-dependent plasticity at corticostriatal connections: Evidence for physiological longterm potentiation. Proceedings of the National Academy of Sciences, 94, 7036-7040.

Cohen, N. J., \& Eichenbaum, H. (1993). Memory, amnesia, and the hippocampal system. Cambridge, MA: MIT Press.

CoHEN, N. J., \& SQUIRE, L. R. (1980). Preserved learning and retention of pattern analyzing skill in amnesics: Dissociation of knowing how and knowing that. Science, 210, 207-210.

COOK, D., \& KESNER, R. P. (1988). Caudate nucleus and memory for egocentric localization. Behavioral \& Neural Biology, 49, 332-343.

FlOOD, J. F., BAKER, M. L., \& DaVIS, J. L. (1990). Modulation of memory processing by glutamic acid receptor agonists and antagonists. Brain Research, 521, 197-202.

Fonnum, F., Storm-Mathiesen, J., \& Divac, I. (1981). Biochemical evidence for glutamate as neurotransmitter in corticostriatal and corticothalamic fibres in the rat brain. Neuroscience, 6, 863-873.

Frey, U., HartmanN, S., \& Matthies, H. (1989). Domperidone, an inhibitor of the D2 receptor, blocks a late phase of an electrically induced long-term potentiation in the CA1 region in rats. Biomedical Biochemical Acta, 48, 473-476.

Garcia-Munoz, M., \& Groves, P. M. (1992). Presynaptic long-term changes in excitability of the corticostriatal pathway. NeuroReport, 3, 357-360.

Gasbarri, A., Sulli, A., \& Packard, M. G. (1997). The dopaminergic mesencephalic projections to the hippocampal formation in the rat. Progress in Neuro-Psychopharmacology \& Biological Psychiatry, 21, 1-22.

Giovannini, M. G., Camilli, F., Mundula, A., Bianchi, L., ColivicCHI, M. A., \& PEPEU, G. (1995). Differential regulation of $N$-methyl$\mathrm{D}$-aspartate and non- $\mathrm{N}$-methyl-D-aspartate receptors of acetylcholine release from rat striatum in vivo. Neumscience, 65, 409-415.

HiRsh, R. (1974). The hippocampus and contextual retrieval of information from memory: A theory. Behavioral Biology, 12, 421-442.

HolsCher, C., ANWYL, R., \& RoWAN, M. J. (1997). Block of theta-burstinduced long-term potentiation by (1S,3S)-1-aminocyclopentane1,3-dicarboxylic acid: Further evidence against long-term potentiation as a model for learning. Neuroscience, 81, 17-22.

Holscher, C., MCGlinchey, L., \& Rowan, M. J. (1996). L-AP4 (L-(+)-2-amino-4-phosphonobutyric acid) induced impairment of spatial learning in the rat is antagonized by MAP4 ((S)-2-amino-2methyl-4-phosphonobutanoic acid). Behavioural Brain Research, 81, 69-79.

Izquierdo, I., da Chuna, C., Rosat, R., Jerusalinsky, D., Ferreira, M. C. B., \& MEdinA, J. H. (1992). Neurotransmitter receptors involved in post-training memory processing by the amygdala, medial septum, and hippocampus of the rat. Behavioral \& Neural Biology, $58,16-26$

Jerusalinsky, D., Ferreira, M. B. C., Walz, R., Da Silva, R. C., Bianchin, M., Ruschel, A., Medina, J. H., \& IzQuierdo, I. (1992).
Amnesia by infusion of glutamate receptor blockers into the amygdala, hippocampus, and entorhinal cortex. Behavioral \& Neural Biology, 58, 76-80.

Kesner, R. P., Bolland, B. L., \& Dakis, M. (1993). Memory for spatial locations, motor responses, and objects: Triple dissociation among the hippocampus, caudate nucleus, and extrastriate visual cortex. Experimental Brain Research, 93, 462-470.

KIM, M., \& MCGAUGH, J. L. (1992). Effects of intra-amygdala injections of NMDA receptor antagonists on acquisition and retention of inhibitory avoidance. Brain Research, 585, 35-48.

Krebs, M. O., Desce, J. M., Kemel, M. L., Gauchy, C., Godeheu, C., Cheramy, F., \& GlowinsKI, J. (1991). Glutamatergic control of dopamine release in the rat striatum: Evidence for presynaptic $N$-methyl$\mathrm{D}$-aspartate receptors on dopaminergic nerve terminals. Journal of Neurochemistry, 56, 81-85.

LIANG, K. C. (1994). Involvement of hippocampal NMDA and AMPA receptors in acquisition, formation, and retrieval of spatial memory in the Morris water maze. Chinese Journal of Physiology, 37, 201-212.

Liang, K. C., HoN, W., \& Davis, M. (1994). Pre- and posttraining infusion of $N$-methyl-D-aspartate receptor antagonists into the amygdala impair memory in an inhibitory avoidance task. Behavioral Neuroscience, 108, 241-253.

MAREN, S. (1995). Properties and mechanisms of long-term synaptic plasticity in the mammalian brain: Relationships to learning and memory. Neurobiology of Learning \& Memory, 63, 1-18.

MarTinez, J. L. (1986). Memory: Drugs and hormones. In J. L. Martinez \& R. P. Kesner (Eds.), Learning and memory: A biological view (pp. 127-155). San Diego: Academic Press.

MatsuoKa, N., \& AIGNER, T. G. (1996). Glutamatergic-cholinergic interaction in visual recognition memory of rhesus monkeys. NeuroReport, 7, 565-568.

MCDonald, R. J., \& White, N. M. (1993). A triple dissociation of memory systems: Hippocampus, amygdala, and dorsal striatum. Behavioral Neuroscience, 107, 3-22.

MCDONALD, R. J., \& WHITE, N. M. (1994). Parallel information processing in the water maze: Evidence for independent memory systems involving dorsal striatum and hippocampus. Behavioral \& Neural Biol$o g y, 61,260-270$.

McEACHeRn, J. C., \& Shaw, C. A. (1996), An alternative to the LTP orthodoxy: A plasticity-pathology continuum model. Brain Research Reviews, 22, 51-92.

MCGaUGH, J. L. (1966). Time-dependent processes in memory storage. Science, 153, 1351-1358.

MCGAUGH, J. L. (1973). Drug facilitation of learning and memory. Annual Review of Pharmacology, 13, 229-240.

MCGAUGH, J. L. (1989). Dissociating learning and performance: Drug and hormone enhancement of memory storage. Brain Research Bulletin, 23, 339-345.

MEdina, J. H., \& IzQuiERDo, I. (1995). Retrograde messengers, longterm potentiation and memory. Brain Research Reviews, 21, 185-194.

Mele, A., Castellano, C., Cestari, V., \& Oliverio, A. (1995). Interaction between the NMDA competitive antagonist CPP and the dopamine system in one-trial inhibitory avoidance in c57BL/6 mice Neurobiology of Learning \& Memory, 63, 143-148.

Miserendino, M. J. D., Sananes, C. B., Melia, K. R., \& Davis, M. (1990). Blocking of acquisition but not expression of conditioned fearpotentiated startle by NMDA receptor antagonists in the amygdala. Nature, 345, 716-718.

Mishikin, M., \& Petri, H. L. (1984). Memories and habits: Some implications for the analysis of learning and retention. In L. R. Squire \& N. Butters (Eds.), Neuropsychology of memory (pp. 287-296). New York: Guilford.

Morris, R. G. M., ANDERSON, E., LyNCh, G. S., \& BAUDRY, M. (1986) Selective impairment of learning and blockade of long term potentiation by an $N$-methyl-D-aspartate receptor antagonist, AP5. Nature, 319, 774-776.

Morris, R. G. M., Garrud, P., RaWlins, J. N. P., \& O'KeEFe, J. (1982) Place navigation impaired in rats with hippocampal lesions. Nature, 297, 681-683.

Morris, R. G. M., Halliwell, R. F., \& Bowery, N. (1989). Synaptic 
plasticity and learning II: Do different kinds of plasticity underlie different kinds of learning? Neuropsychologia, 27, 41-59.

Navarro, C. E., Cabrena, R. J., \& Donoso, A. O. (1995). Interaction between glutamate and GABA on $3 \mathrm{H}$-noradrenaline release from rat hypothalamus. Brain Research Bulletin, 37, 119-126.

Ohno, M., Yoshimatsu, A., Kobayashi, M., \& Watanabe, S. (1996) Beta-adrenergic dysfunction exacerbates impairment of working memory induced by hippocampal NMDA receptor blockade in rats. European Journal of Pharmacology, 307, 21-26.

O'KEEFE, J., \& NADEL, L. (1978). The hippocampus as a cognitive map. New York: Oxford University Press.

Ottersen, O. P., Huelle, O. P., Osen, K. K., \& LaAke, J. H. (1995). Amino acid transmitters. In G. Paxinos (Ed.), The rat nervous system (pp. 1017-1040). New York: Academic Press.

OtTersen, O. P., \& Storm-Mathisen, J. (1989). Excitatory and inhibitory amino acids in the hippocampus. In V. Chan-Palay \& C. Kohler (Eds.), The hippocampus: New vistas (pp. 97-117). New York: Alan R. Liss.

Packard, M. G., Cahill, L., \& McGaugh, J. L. (1994). Amygdala modulation of hippocampal-dependent and caudate nucleus-dependent memory processes. Proceedings of the National Academy of Sciences, 91, 8477-8481.

PaCKard, M. G., Hirsh, R., \& WhITE, N. M. (1989). Differential effects of fornix and caudate nucleus lesions on two radial maze tasks: Evidence for multiple memory systems. Journal of Neuroscience, 9 , 1465-1472.

PaCkard, M. G., \& MCGaugh, J. L. (1992). Double dissociation of fornix and caudate nucleus lesions on acquisition of two water maze tasks: Further evidence for multiple memory systems. Behavioral Neuroscience, 106, 439-446.

PACKARD, M. G., \& McGaUgh, J. L. (1994). Qunipirole and $d$-amphetamine administration posttraining enhances memory on spatial and cued discriminations in a water maze. Psychobiology, 22, 54-60.

PaCkard, M. G., \& MCGaugh, J. L. (1996). Inactivation of the hippocampus or caudate nucleus with lidocaine differentially affects expression of place and response learning. Neurobiology of Learning \& Memory, 65, 65-72.

PaCkard, M. G., \& TEATHER, L. A. (1997a). Double dissociation of hippocampal and dorsal striatal memory systems by posttraining intracerebral injections of 2-amino-5-phosphonopentanoic acid. Behavioral Neuroscience, 111, 543-551.

Packard, M. G., \& Teather, L. A. (1997b). Post-training injections of MK-801 produce a time-dependent impairment of memory in two water maze tasks. Neurobiology of Learning \& Memory, 68, 42-50.
Packard, M. G., \& TEather, L. A. (1998). Amygdala modulation of multiple memory systems: Hippocampus and caudate-putamen. Neurobiology of Learning \& Memory, 69, 163-203.

PACKARD, M. G., \& White, N. M. (1990). Lesions of the caudate nucleus selectively impair acquisition of "reference memory" in the radial maze. Behavioral \& Neural Biology, 53, 39-50.

PACKARD, M. G., \& WhITE, N. M. (1991). Dissociation of hippocampus and caudate nucleus memory systems by posttraining intracerebral injection of dopamine agonists. Behavioral Neuroscience, 105, 295-306.

Packard, M. G., Winocur, G., \& White, N. M. (1992). The caudate nucleus and acquisition of win-shift radial-maze behavior: Effect of exposure to the reinforcer during maze adaptation. Psychobiology, 20, 127-132.

PaxinOs, G., \& WATSON, C. (1986). The rat brain in stereotaxic coordinates (2nd ed.). San Diego: Academic Press.

Riedel, G., Wetzel, W., \& ReymanN, K. G. (1996). Metabotropic glutamate receptors in spatial and nonspatial learning in rats studied by means of agonist and antagonist application. Learning \& Memory, 2, 243-265.

Robinson, G. S., Jr., Crooks, G. B., Jr., Shinkman, P. G., \& GalLAGHER, M. (1989). Behavioral effects of MK-801 mimic deficits associated with hippocampal damage. Psychobiology, 17, 156-164.

Shapiro, M. L., \& Caramanos, Z. (1990). NMDA antagonist MK-801 impairs acquisition but not performance of spatial working and reference memory. Psychobiology, 18, 231-243.

Sutherland, R. J., \& Rudy, J. W. (1989). Configural association theory: The role of the hippocampal formation in learning, memory, and amnesia. Psychobiology, 17, 129-144.

Ward, L., Mason, S. E., \& Abraham, W. C. (1990). Effects of the NMDA antagonists CPP and MK-801 on radial arm maze performance in rats. Pharmacology, Biochemistry \& Behavior, 35, 785-790.

Whishaw, I. Q., Mittleman, G., Bunch, S. T., \& DunNeTt, S. B. (1987). Impairments in the acquisition, retention, and selection of navigation strategies after medial caudate-putamen lesions in rats. Behavioural Brain Research, 24, 125-138.

Whitton, P. S., Maione, S., Biggs, C. S., \& Fowler, L. J. (1994) $N$-methyl-D-aspartate receptors modulate extracellular dopamine concentration and metabolism in rat hippocampus and striatum in vivo. Brain Research, 635, 312-316.

(Manuscript received August 4, 1998; revision accepted for publication November 30,1998 .) 